\title{
Coronary interventions in Europe 1992
}

\author{
C. Röthlisberger and B. Meier on behalf of the working group on Coronary Circulation of the \\ EUROPEAN SOCIETY OF CARDIOLOGY
}

Cardiology, University Hospital, Bern, Switzerland

KEY WORDS: Coronary angiograms, PTCAs, stents in Europe 1992.

The general practice of coronary interventions is influenced by various aspects, traditional, cultural, socioeconomic and personal. The aim of this survey was to collect the data on coronary interventions in all member countries of the European Society of Cardiology. The data from 12 of the 35 national members were missing or grossly incomplete and were therefore excluded from the analysis.

Coronary angiography The total number of coronary angiograms was reported as 683888 , an incidence of $1009 \pm 1021$ per million inhabitants (range 9 (Romania) to 3076 (Germany)). Germany (246 115 cases), France (144 754), the United Kingdom (76 296), Italy (45 517) and Spain (43 495) registered 81\% of all the coronary angiograms performed.

Percutaneous transluminal coronary angioplasty (PTCA) The total number of reported PTCAs was 147729 , which on average accounted for $19 \pm 11 \%$ (range 2 (Lithuania) to 53\% (Netherlands)) of the coronary angiograms. Most of the PTCAs (82\%) were confined to a single vessel. The highest incidence of multivessel PTCA was reported from Slovakia (28\%). PTCA took place immediately after the diagnostic study in only $18 \%$ of cases. Adjusted per capita, Germany ranked first with 703 PTCAs per million inhabitants, followed by Iceland (619), France (614), Belgium (568) and Austria (485). A major in-hospital complication was reported in $2.5 \%$ of the patients undergoing PTCA: $0.4 \%$ hospital deaths, $1.0 \%$ emergency CABGs and $1.1 \%$ myocardial infarctions.

New devices Stents were implanted in 3211 patients $(2.7 \%$ of all PTCA patients), equally distributed between emergency situations (53\%) and elective procedures. Other interventional devices were applied in 4133 cases $(2.8 \%$ of all PTCA cases): directional atherectomy, rotablator, transluminal extraction catheter, laser and Rotacs accounted for 1452, 1232, 55, 558 and 222, respectively. Coronary ultrasound (1350 cases) and coronary angioscopy (373 cases) were rarely performed.

Coronary artery bypass grafting (CABG) A total of 63477 patients underwent $C A B G$ in the reporting centres resulting in a PTCA/CABG ratio of 2.3. A significant under-reporting of surgery in the participating centres must be assumed.

Conclusions Although partial reporting might bias conclusions, several findings of this survey are noteworthy: (I) PTCA was a well accepted treatment for coronary artery disease, (2) PTCA was applied more frequently than CABG, (3) there was an extremely wide range of coronary angiography and PTCA performed per million inhabitants, (4) the most common additional procedure was stent implantation, but other new devices were only rarely applied.

\section{Introduction}

While coronary artery surgery has been routine clinical practice for about 25 years ${ }^{[1.2]}$, percutaneous transluminal coronary angioplasty (PTCA) was only developed in the late $1970 \mathrm{~s}^{[3]}$. The latter expanded to interventional cardiology during the 1980 s by being applied in an ever increasing number of patients and heart problems. Cardiac surgery and interventional cardiology are mostly complementary in modern therapy of coronary, valvular and congenital heart disease and have gained wide acceptance by physicians and patients. Each technique needs continuous evaluation in respect of immediate and long-term results including side effects, morbidity, and mortality. In addition, it is interesting to examine the use of such procedures in different populations and nations

Manuscript submitted 8 August 1994, and accepted 28 October 1994.

Correspondence. Bernhard Meier, MD. Professor and Head of Cardıology. University Hospital. 3010 Bern, Switzerland and to compare these figures adjusted per number of inhabitants. This allows several conclusions to be drawn, which will be necessary for planning facilities, establishing guidelines and controlling quality. It is important to keep in mind that the utilization of such expensive and sophisticated procedures is influenced by various factors - traditional, cultural, socioeconomic, political, and even personal - in addition to the incidence and prevalence of the disease.

An estimated 300000 percutaneous transluminal coronary angioplasties (PTCAs) were performed in the United States in $1990^{[4]}$; accurate numbers, however, are not available. Several surveys regarding the number of coronary interventions in Europe $e^{[5]}$ or individual countries ${ }^{[6-9]}$ have been performed and published recently, and this survey, mandated by the board of the European Society of Cardiology, was intended to poll the interventions in all countries belonging to the European Society of Cardiology. The principal aim of 
Table I Countries with no or grossly incomplete reporting of data

\begin{tabular}{lll}
\hline Algeria & Egypt & Norway \\
Croatia & Hungary & Portugal \\
Cyprus & Ireland & Russia \\
Denmark & Morocco & Tunisia \\
\hline
\end{tabular}

this survey was to analyse and compare the data on coronary interventions in the participating countries and to form a solid information base for future years.

\section{Methods}

In March 1993 a detailed questionnaire was sent to all the presidents of the national cardiac societies belonging to the European Society of Cardiology. They were asked to send a copy to all the centres performing coronary angiograms and coronary interventions in their country, to collect all the data from those centres, to pool the figures and to list them on a summary questionnaire. Attached to the questionnaire were instructions and examples showing how to complete the form.

The following definitions were used:

Coronary angiograms: Diagnostic catheterizations with coronary angiography, irrespective of whether performed in conjunction with other diagnostic studies or PTCA.

PTCA: Coronary angioplasty procedures (cases), irrespective of what instrument was used, how many lesions or vessels were dilated, whether a diagnostic study was carried out during the same session and whether the patient had additional procedures during the same year. PTCA ad hoc: PTCA performed in one session with the diagnostic study producing the indication for PTCA. Myocardial infarction: Elevation of creatine kinase to at least double the upper normal limit.
Single vessel PTCA: PTCA of one or more lesions in one vessel.

Multivessel PTCA: PTCA of more than one vessel in the same session.

PTCA for acute infarction: Rescue PTCA with or without fibrinolysis (direct PTCA).

The initial deadline for reporting back was May 1993. Where data had not been produced by this date a reminder was issued to the presidents or the persons assigned by them. If reporting back was still unforthcoming or incomplete after another 3 months additional reminders were sent out bimonthly, or the responsible persons were contacted directly. In April 1994 the registry was closed.

\section{Results}

Reports from 12 of the 35 nations are missing or grossly incomplete. These 12 (Table 1) were therefore excluded from the analysis. The data of the 23 remaining countries, with a total population of 507.7 millions, form the body of this paper. All important countries in terms of interventional activity are included.

\section{GENERAL RESULTS}

The total number of coronary angiograms and PTCAs were reported to be 683888 and 147729 , respectively. The vast majority of PTCAs were performed electively $(89 \%)$ and were confined to a single vessel $(82 \%)$. PTCA for acute infarction was attempted in 2899 cases. Major complications were reported in $2.5 \%$ : hospital deaths accounted for $0.4 \%$, emergency coronary artery bypass grafting (CABG) for $1.0 \%$ and myocardial infarction for $1 \cdot 1 \%$. New devices including stents (3211 cases), directional atherectomy (1452), rotablator

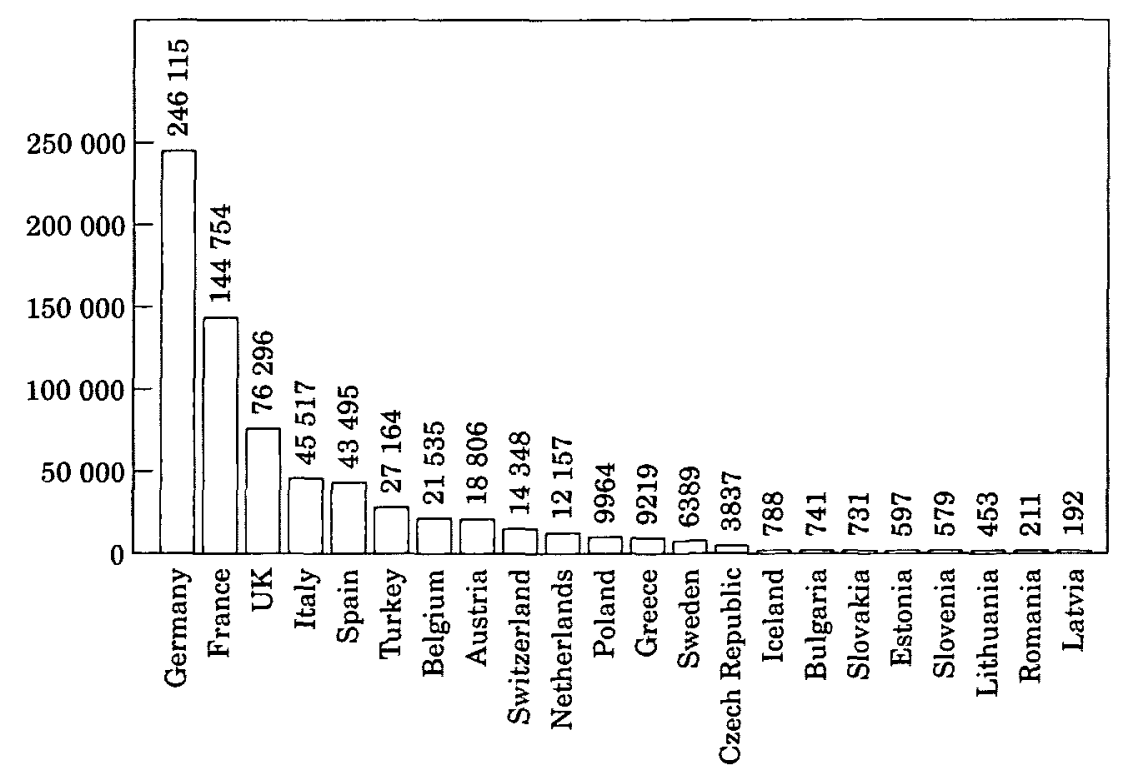

Figure I Coronary angiograms per country. 


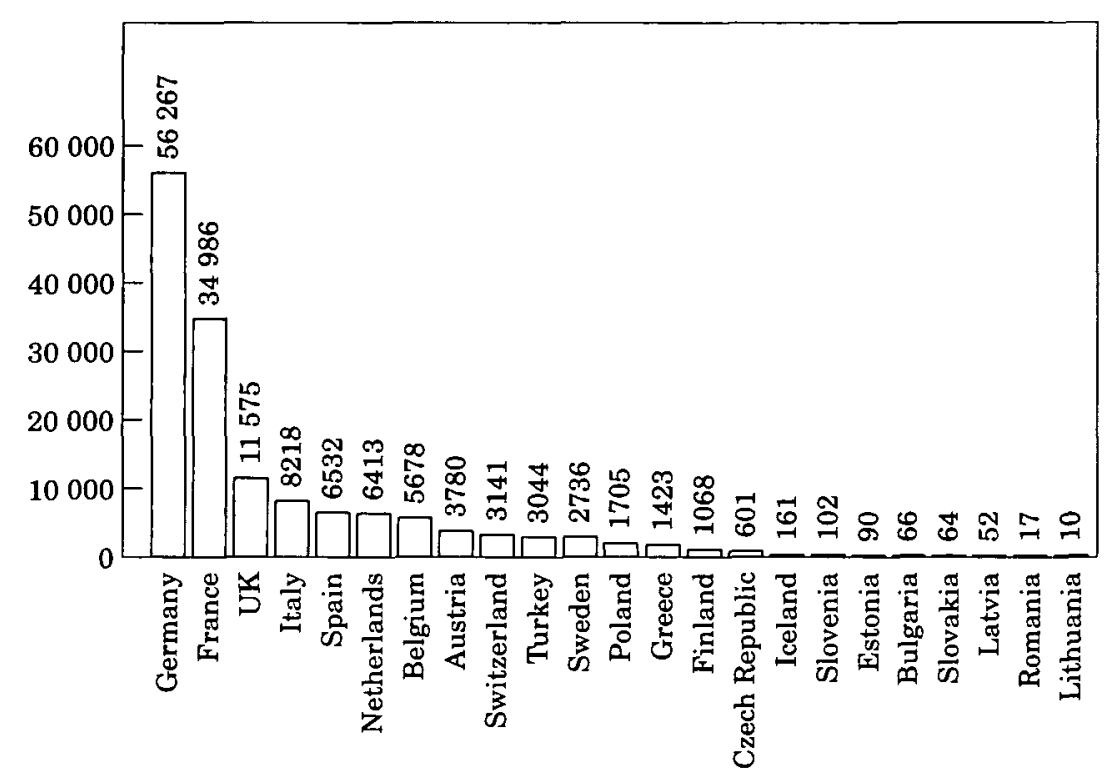

Figure 2 PTCAs per country.

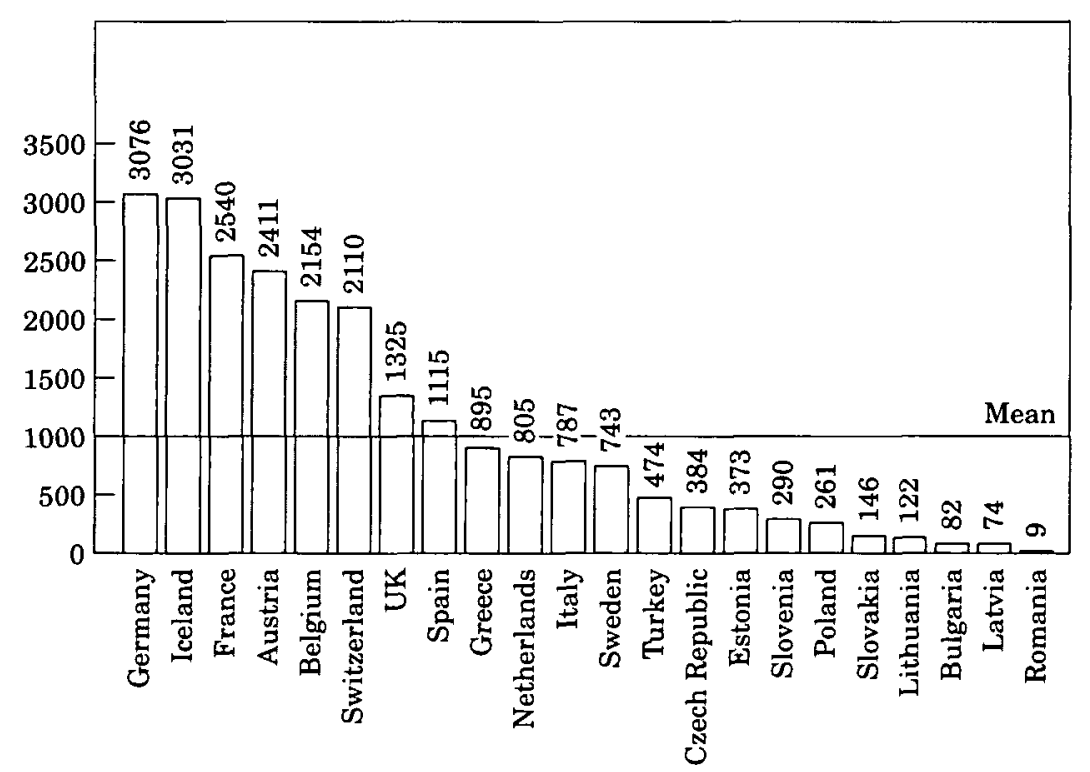

Figure 3 Coronary angiograms per million inhabitants and country.

(1232), laser (558), Rotacs (222), transluminal extraction catheter (TEC, 55), as well as coronary ultrasound (1350) and coronary angioscopy (373) were involved in $5.7 \%$ of all PTCAs. During the same period 63477 coronary artery bypass grafting (CABG) procedures were reported.

\section{DATA ANALYSED PER NATION}

The five countries Germany, France, United Kingdom, Italy, and Spain performed $81 \%$ of all coronary angiograms and $80 \%$ of all PTCAs (Figs 1 and 2). The European mean was $1009 \pm 1021$ coronary angiograms per million inhabitants. The highest incidence of coronary angiograms per million inhabitants was reported from Germany followed by Iceland and France (Fig. 3). These three nations also reported the highest rate of PTCA per million inhabitants (Fig. 4), followed by Belgium, Austria, Switzerland, and the Netherlands. The European mean of PTCAs per million inhabitants was $233 \pm 236$. The ratio of PTCAs per coronary angiograms was highest in The Netherlands (53\%) and Sweden (43\%) while the European mean was $19 \pm 11 \%$ (Fig. 5). Compared to the countries in western Europe, coronary angiograms and PTCAs were performed less frequently in eastern Europe. The percentage of multivessel PTCA is shown in Fig. 6. It ranged from $28 \%$ in Slovakia to $0 \%$ in Lithuania and averaged $12 \pm 8 \%$ 


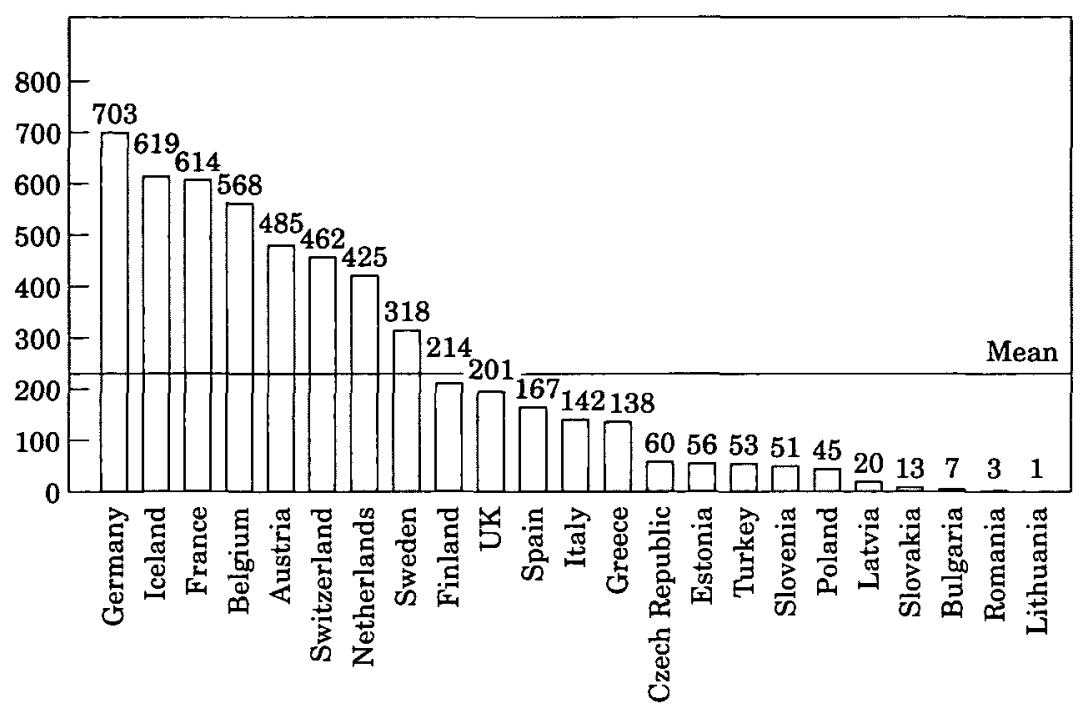

Figure 4 PTCAs per million inhabitants and country.

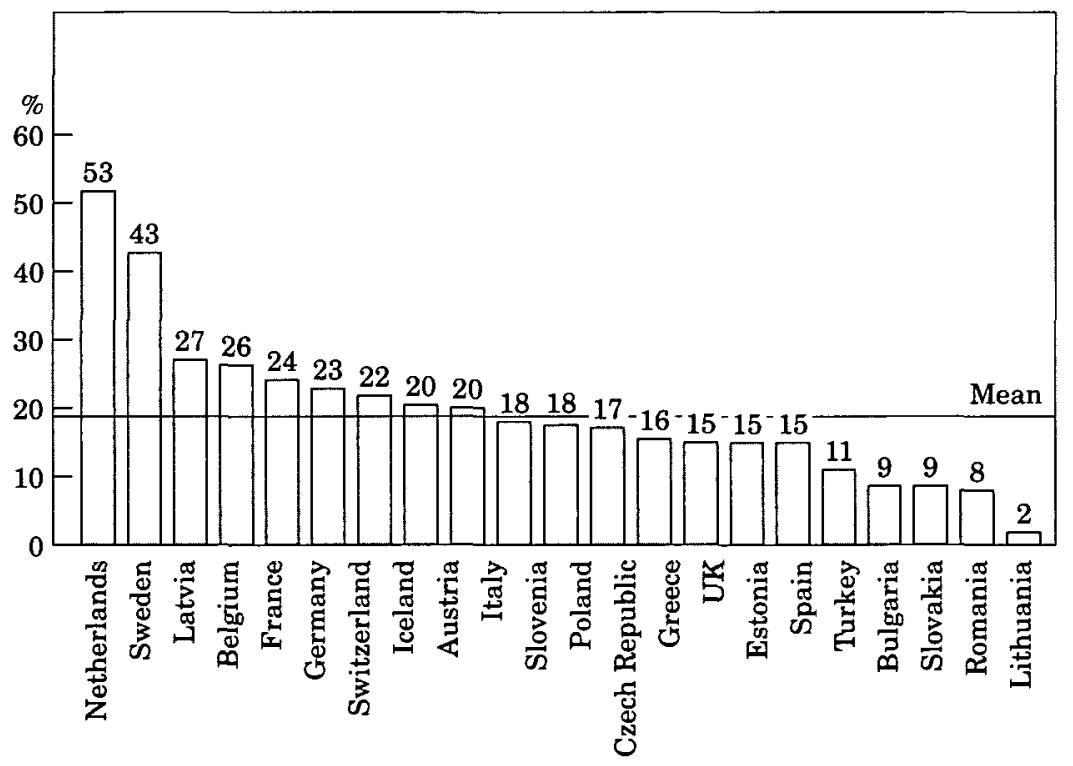

Figure 5 PTCAs per coronary angiograms and country.

when including also the countries not shown in Fig. 6 . Ad hoc PTCAs were reported in $43 \%$ from Switzerland followed by Austria (39\%), Estonia (27\%) and Belgium (23\%) (Fig. 7).

\section{NEW THERAPEUTIC DEVICES}

The stent was the most frequently used new therapeutic device, accounting for $2.7 \%$ of all PTCAs. The indications were fairly equally distributed between elective (47\%) and emergency (53\%) situations. Italy, Germany, France, Spain, and the United Kingdom implanted $77 \%$ of all stents (Fig. 8). There were no reports of stent implantations in Eastern Europe except from Poland ( 2 stents) and Bulgaria (1 stent). Coronary stenting per PTCA (Fig. 9) averaged $2 \cdot 8 \pm 2 \cdot 0 \%$ in the stent implanting countries, the highest incidences being in Italy (7.9\%), Spain (5.7\%), and Switzerland (3.6\%). The other new coronary devices are summarized in Fig. 10. They were applied in only 14 countries and the majority of the procedures were carried out in Germany or France. Poland again was the only Eastern European country using several of these sophisticated and expensive techniques.

\section{NEW DIAGNOSTIC DEVICES}

New diagnostic devices played a minor role and were applied in only $1.2 \%$ of all PTCAs. Germany and France together accounted for $58 \%$ of these 


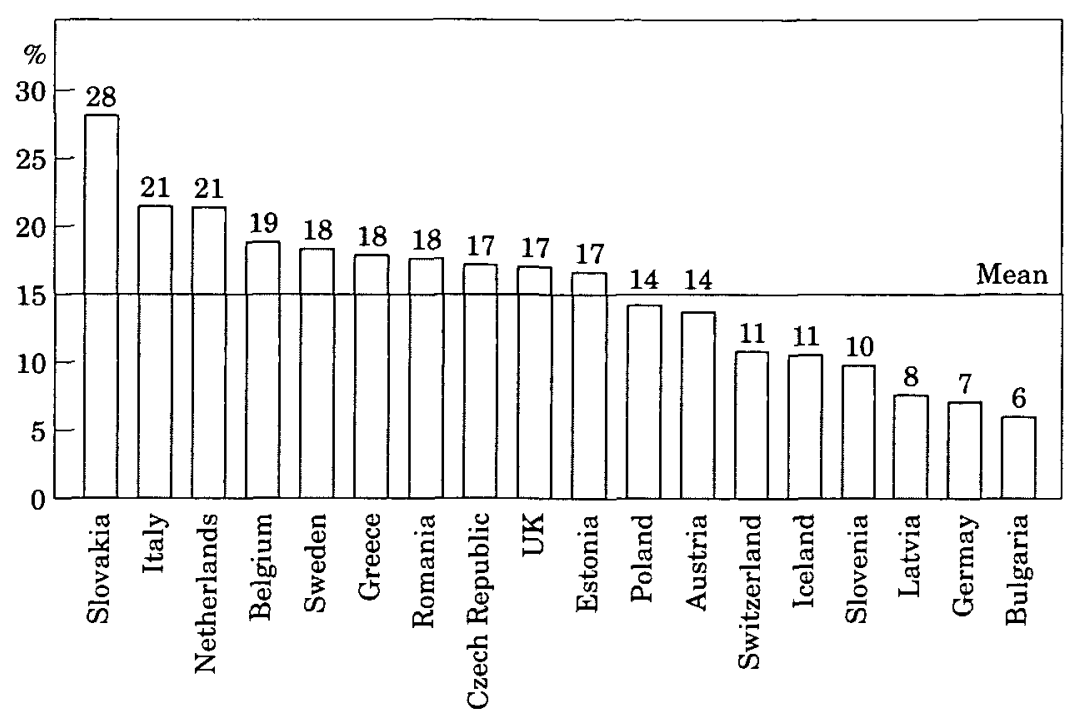

Figure 6 Multivessel PTCAs per total PTCAs and country.

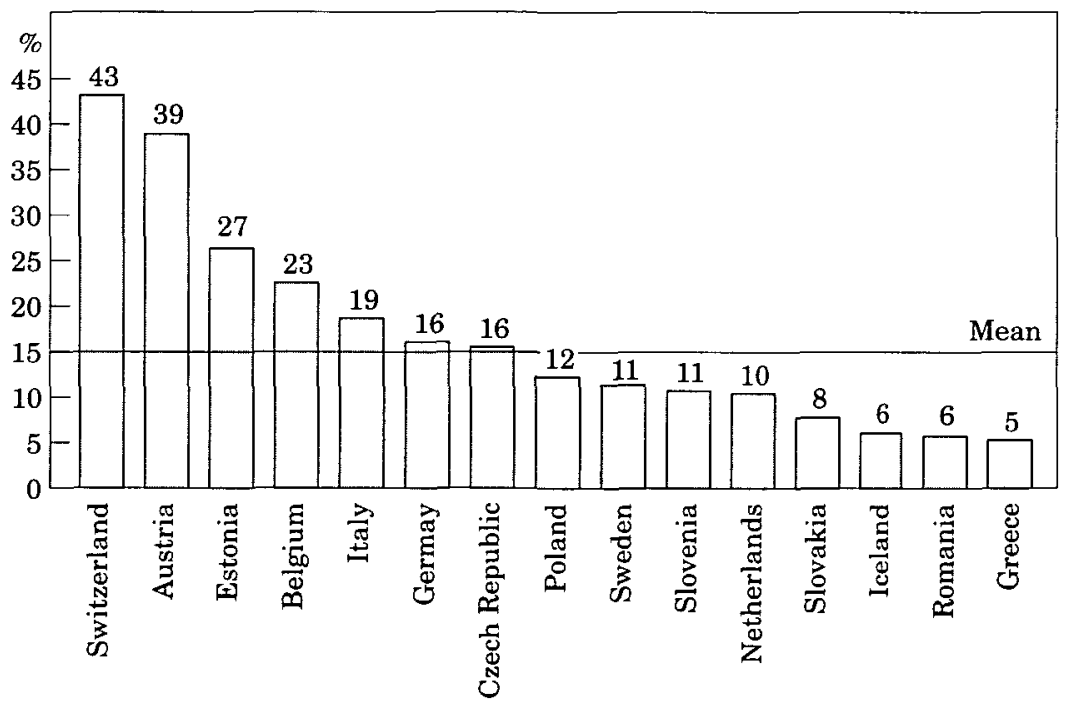

Figure 7 Ad hoc PTCAs per total PTCAs and country.

applications. Coronary ultrasound with 1350 applications was by far the preferred new diagnostic tool in interventional cardiology, compared to 373 cases of coronary angioscopy. Except for Sweden, all countries applying both techniques performed more coronary ultrasound examinations than coronary angioscopies (Figs 11 and 12).

\section{Discussion}

The incompleteness of the reporting is a drawback of this survey. Several countries, for instance, Austria, Switzerland, and The Netherlands have a long tradition of performing similar surveys of cardiac interventions, and can rely on an excellent reporting system resulting in accurate data. The quality of reporting in other countries is hard to assess. In general, this seemed to be better from the smaller countries. Adverse events, such as complications of PTCA, are presumed to be underreported. Only a regularly updated data bank run by professionals not directly involved in the procedures at each institution could overcome this problem. As the number of CABGs was collected by the referring cardiologists, under-reporting could be high. All these methodological limitations must be kept in mind when analysing the data of this survey. Quality control is clearly beyond its scope and potential.

In general the number of coronary angiograms, PTCAs, and newer interventional techniques was at its height in the west and markedly declined the further east the European country. However, even among the wealthy western European countries. the figures for coronary angiograms and PTCAs per capita vary considerably. The ranking is at least partially affected by the 


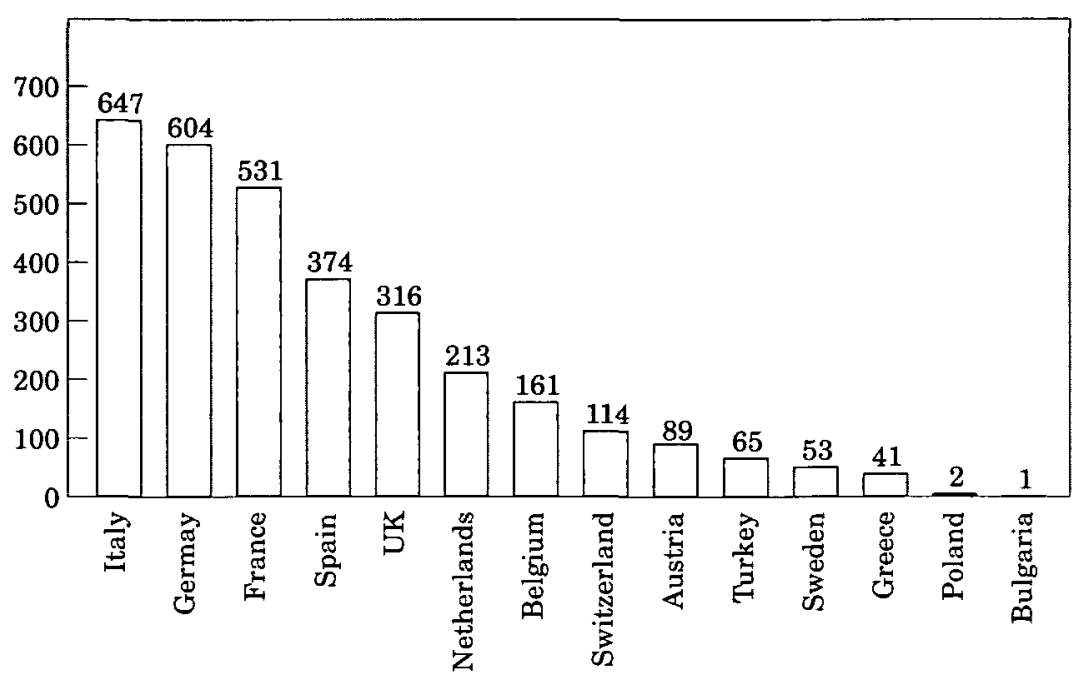

Figure 8 Stent implantations per country.

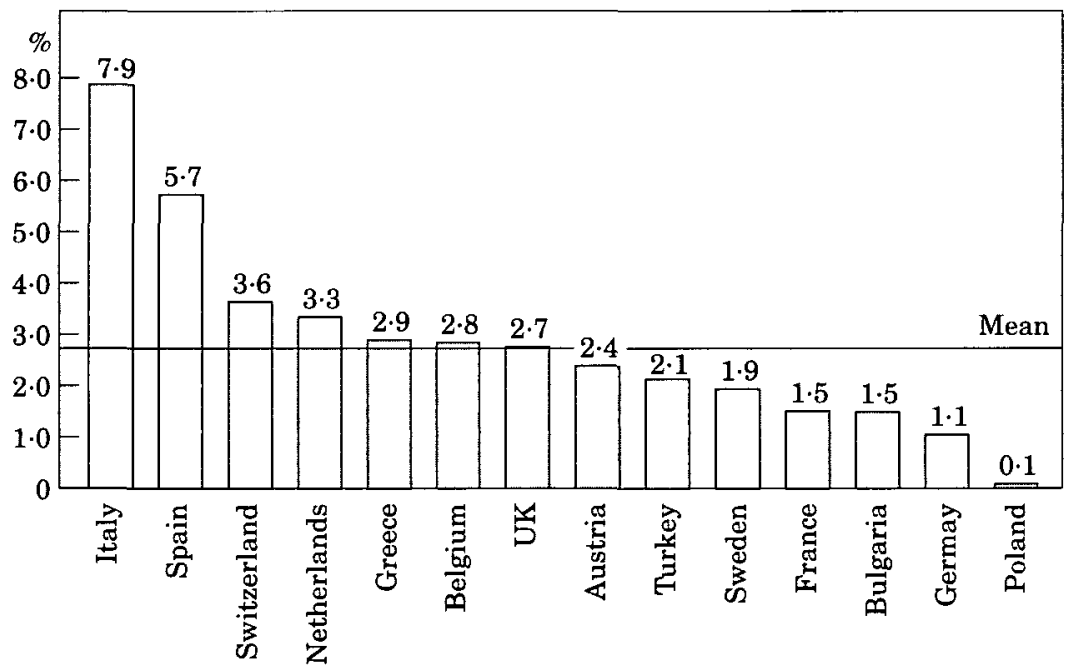

Figure 9 Coronary stent implantations per total PTCAs per country.

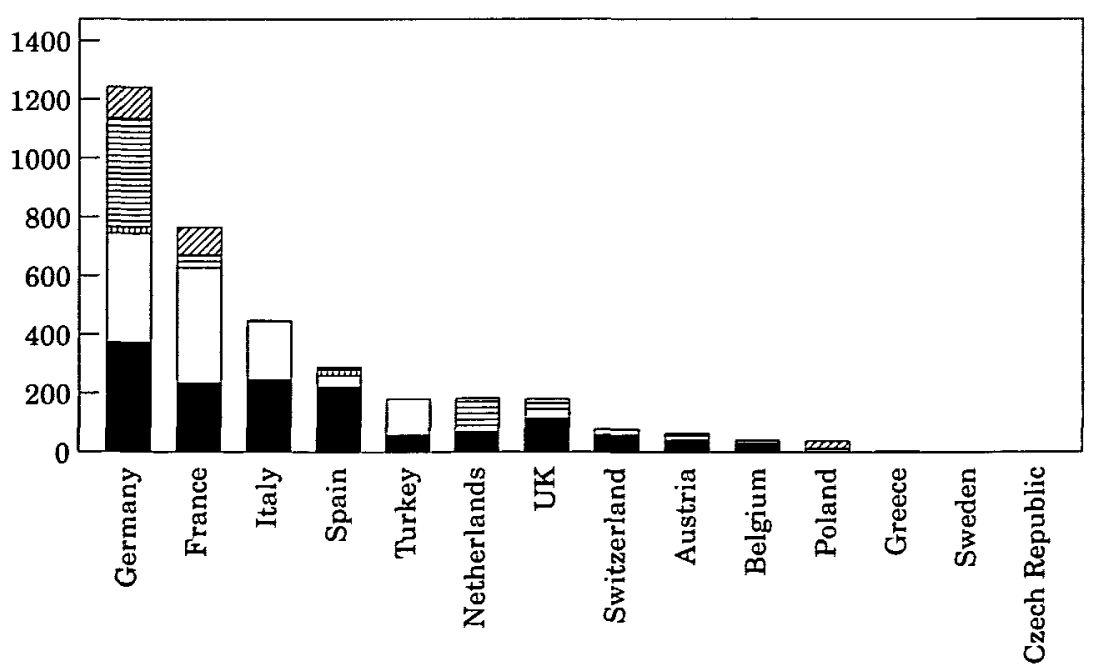

Figure 10 Other new therapeutic devices (except stents) per country. $=$ Rotacs; $=$ laser; $\square=$ TEC (transluminal extraction catheter); $\square=$ rotablator; $\mathbf{D = d i r e c t i o n a l ~ a t h e r e c t o m y . ~}$ 


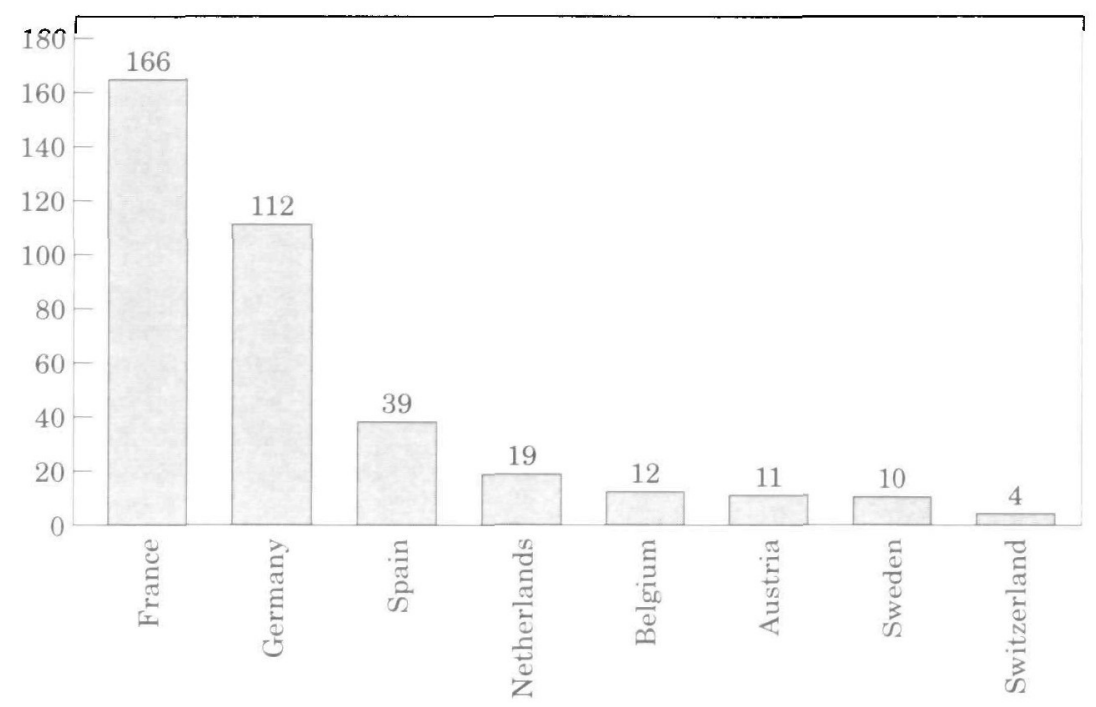

Figure 11 Coronary ultrasound per country

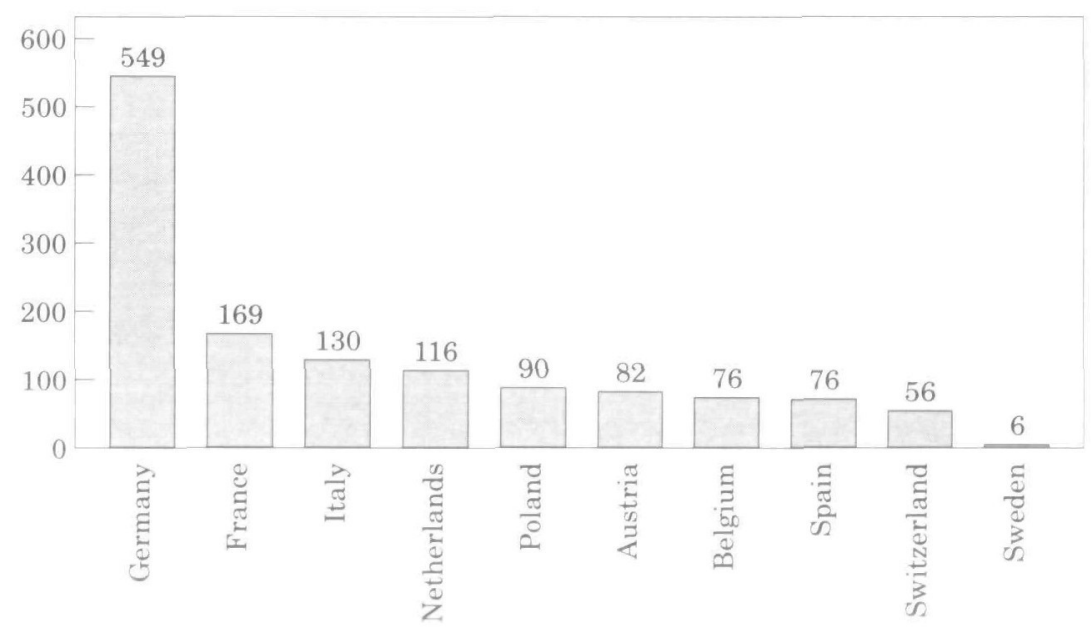

Figure 12 Coronary angioscopy per country.

accuracy of reporting. For example Iceland, with only one active interventional cardiologist, and other smaller countries with a long-standing tradition regarding feedback have almost no missing data and therefore rank among the most active when corrected per capita. Relating PTCAs to the number of coronary angiograms performed per country is very revealing. While most countries perform a PTCA in 15 to $28 \%$ of their coronary angiograms, the figures for The Netherlands and Sweden are 53 and $43 \%$, respectively. Two interpretations are possible: either there is under-reporting of diagnostic studies in these two countries (probably from non-interventional laboratories) or PTCAs are applied in a very broad spectrum of indications. It is surprising that Slovakia ranks first in the percentage of multivessel PTCAs, although only a total of 64 PTCAs were carried out. This may suggest a misinterpretation of the definition of multivessel PTCA in that country.

Among the new therapeutic devices, the coronary stent seemed to be the most promising tool for the interventional cardiologist. The percentage of stents per PTCA varied largely even among the five principal stenting nations: while stents were implanted in $7.9 \%$ in Italy, Germany reported only a $2.0 \%$ incidence, although the total amount of stents implanted is comparable. Other new therapeutic devices played a minor role in daily interventional practice and were mostly applied in some wealthy western countries.

In conclusion, PTCA has become a well accepted treatment for coronary artery disease in Europe and is reported more frequently than $\mathrm{CABG}$ in this survey. An extremely wide range of coronary angiograms and PTCAs were performed per million inhabitants, with a definite decline from West to East in Europe. The most common additional device in interventional cardiology is the stent, other newer devices being applied only rarely.

The results of such a survey are highly dependent on the completeness and accuracy of each questionnaire. It must be emphasized, therefore, that the better and more complete the reporting the more valuable is the message 
of such a survey. This implies no loss of data, unbiased data collection at each centre and prompt and complete reporting to the collecting agency. In future it is hoped that every centre in Europe will comply to produce even more valuable yearly reports.

\section{References}

[1] Favaloro RG. Saphenous vein graft in the surgical treatment of coronary artery disease: operative technique. J Thorac Cardiovasc Surg 1969; 58: 178-85.

[2] Garret HE, Dennis EW, DeBakey ME. Aortocoronary bypass with saphenous vein graft: seven-year follow-up. JAMA 1973; 223: 792-4

[3] Gruentzig A. Transluminal dilatıon of coronary-artery stenosis. Lancet 1978; I: 263.
[4] Graves EJ. National hospital discharge survey: Annual summary, 1991. National Center for Health Statistics 1993; DHHS publication (PHS): 93-1775: 44.

[5] Unger F. European survey on open heart surgery, PTCA and heart catheterization 1992. Ann Acad Sci Artium Eur 1993; vol. 6.

[6] Van den Brand $\mathrm{M}$ and the European Angioplasty group: Utilization of Coronary angioplasty and cost of angioplasty disposables in 14 western European countries. Eur Heart J 1993; 14: 391-7.

[7] Rouvinez G, Bertel O, Urban P, Meier B. Herzeingriffe in der Schweiz 1992. Schweiz Med Wschr 1994; 124: 1284-94.

[8] Mühlberger V, Probst P, Pachinger O. Statistical analysis of invasive cardiology for Austria in 1992 as an approach to quality assessment. J Interven Cardiol 1994 7: 17-24.

[9] Gleichmann U, Mannebach H, Lichtlen P. 9. Bericht über Struktur und Leistungszahlen der Herzkatheterlabors in der Bundesrepublik Deutschland. Z Kardiol 1994; 83: 74-8. 